\title{
Chopperless Fault Ride-Through Control for DC Microgrids
}

\author{
Yanghong Xia, Member, IEEE, Teng Long, Member, IEEE
}

\begin{abstract}
The de microgrid should remain connected to the ac utility grid to support the grid stability during faults. However, the bidirectional power flow between the utility grid and the dc microgrid will cause either high-voltage or low-voltage faults at the dc bus. It is difficult to control a large number of heterogeneous sources at the dc bus to ride through the fault, as well as exporting reactive power or reactive current to the utility grid. This paper proposes a chopperless fault ride-through control strategy for the dc microgrid. The proposed control strategy utilizes the controllability of dc microgrids without using chopper circuit on the dc side to balance the system power. Following goals are achieved by this control strategy: 1) maximizing the output reactive power to the utility grid; 2 ) reducing the dc bus voltage ripples; 3) realizing the decentralized emergency power control among different distributed generators. The effectiveness of the proposed control method has been validated through related case studies in both simulation and hardware-in-loop (HIL) tests.
\end{abstract}

Index Terms-Fault ride-through, dc microgrids, chopper circuit, maximize reactive power, emergency power control.

\section{INTRODUCTION}

IINCE the dc distributed generators (DGs) and dc loads like P PV generators, data center, electric vehicles and so on are continuously growing, dc microgrids are grasping more and more attention with their high reliability and high efficiency. Penetration of dc microgrids in the utility grid is expected to be prevailing in the next few years [1]-[3]. Nowadays, the common operation codes of dc micogrids require the system to switch into the islanded mode once the voltage sags of the external utility grid are detected even the instantaneous faults. However, if the dc microgrids have account for a large portion of the entire grid, the dc microgrids should remain in grid-connected mode for a specified period to support the transient stability of the utility grid, especially for utilities in remote areas. That is, dc microgrids should be equipped with the fault ride-through (FRT) function.

As shown in Fig.1, the dc system is connected to the utility grid through a bidirectional power converter (BPC). When voltage sags occur at the utility grid, the BPC needs to remain operating without tripping, which is similar to the FRT of some large-capacity grid-connected DGs. In [4]-[6], the relationship

This work is supported in part by the National Key R\&D Program of China (2017YFB0903300), in part by the National Natural Science Foundation of China (52007162), in part by the Project founded by China Postdoctoral Science Foundation (2019M660139, 2020T130572). (Corresponding author: Teng Long.)

Y. Xia and T. Long are with the Department of Engineering, University of Cambridge, Cambridge CB2 1TN, U.K. (e-mail: royxiayh@126.com, t1322@cam.ac.uk). between the instantaneous power and the sequence currents is derived based on the $d-q$ synchronized frame. Then, different current control strategies such as active power oscillation cancellation, reactive power oscillation cancellation, three-phase currents balance are proposed through solving linear equations to generate proper reference currents. While in [7]-[8], the above relationship is derived based on the $\alpha-\beta$ stationary frame for various current control strategies.

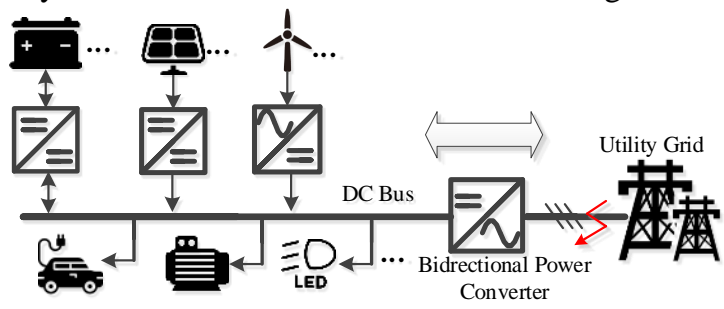

(a)

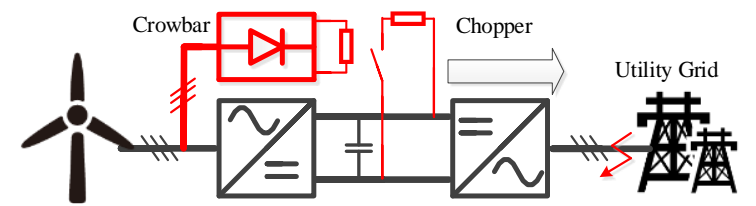

(b)

Fig.1. Comparison between the dc microgrid and the distributed generator under voltage sags. (a) Dc microgrid. (b) Distributed generators.

In addition to the power or current control, the voltage support is also important and required by some grid codes. Focusing on this problem, a voltage support method is proposed based on zero-sequence voltage compensation in [9]. The proposed method considers the resistance of cables in the utility grid and controls both active and reactive power of DGs. In [10]-[11], the relationship between injected currents and terminal voltages is derived for different types of voltage sags. The phase voltages are controlled in balance by coordinating positive and negative reactive currents. Based on the DG's equivalent negative sequence virtual impedance, two methods are designed to compensate unbalanced utility voltages in [12]. The positive-sequence droop control and the negative-sequence droop control are proposed in [13]-[14] to realize the coordinated operation of multiple grid-connected inverters under unbalanced voltage sags.

Since the active power oscillation cancellation has a counter effect to the reactive power oscillation, efforts have been made to find flexible regulation methods to optimize the active and reactive power performance at the same time [15]-[17]. In addition, unbalanced voltage sags will result in the overcurrent at DGs, thus the FRT control must limit the output currents of DGs. In [18]-[19], each phase current is presented through 
TABLE I

COMPARISON WITH EXISTING CONTROL METHODS

\begin{tabular}{ccccccc}
\hline \hline Existing Methods & Generators & Power Balance & Maximize $Q$ & System Cost & AC or DC system & Control Objectives \\
\hline \hline Ref. [4]-[8] & Single & $/$ & Suboptimal & $/$ & AC & Oscillation Suppression \\
Ref. [13]-[14] & Multiple & $/$ & Suboptimal & $/$ & AC & Power Sharing \\
Ref. [15]-[17] & Single & $/$ & Suboptimal & $/$ & AC & $P, Q$ Coordination \\
Ref. [25]-[27] & Single & Crowbar & $/$ & High & AC & Power Balance \\
Ref. [28] & Single & Chopper & $/$ & High & AC & Power Balance \\
Ref. [24], [29] & Single & Chopper, Crowbar & $/$ & High & AC & Power Balance \\
This paper & Multiple & Chopperless & Optimal & Low & DC & Multiple Objectives \\
\hline \hline
\end{tabular}

/: means no mention

positive- and negative-sequence currents based on the $\alpha-\beta$ stationary frame. Then, under the constraint conditions about the maximum current in each phase, the positive- and negative-sequence active/reactive power references can be determined with different control goals. The new nominal power concept is proposed in [20], which depends on the voltage sag depth and is less than the nominal power of the converter. Through this indirect way, the output currents of DGs are limited, but the risk of overcurrent still exists. To avoid solving some complex nonlinear equations, the constraint conditions about the currents are scaled and more conservative reference power is generated to avoid overcurrent [21]. Nevertheless, the above strategies have not considered the dynamics of the dc side and view the dc side as an ideal voltage source.

Another task about the FRT is the power balance control especially for deep ac voltage sags. Since the generated energy by the DG cannot be entirely fed to the grid, the excessive energy will cause overvoltage at the dc-link or overcurrent at the machine (stator for PMSG, rotor for DFIG). The commonly adopted strategies are based on the chopper circuit or crowbar circuit (for wind turbines) [22]-[23] to dissipate the surplus energy as shown in Fig.1 (b). In [24], the operation profile about the chopper and crowbar is introduced, it is concluded that the energy dissipation resistance has great influence on the system dynamics. In [25] and [26], the resistance of the crowbar and its operation duration are optimized to enhance the system performance and power quality. To improve reactive power support during severe grid faults, the resistor of crowbar circuit is replaced by energy storage for DFIGs [27]. Furthermore, through appropriate coordinated control between the energy storage side converter and the rotor side converter, the capacity of the energy storage can be optimized, which can balance system performance and cost. While in [28], the chopper circuit is modified to keep both the dc-link voltage and winding current within an acceptable range at the same time without any fault-current-limiting control strategy. In [29], a coordinated control method between the chopper and crowbar is proposed to enhance the fault ride-through and recovery of DFIG. However, the adoption of the chopper and crowbar will increase the system cost and complexity.

The FRT of dc microgrids exhibits some new challenges, which needs strategies from the viewpoint at the system level. As shown in Fig.1 (a), the power flow between the utility grid and the dc microgrid is bidirectional. Voltage sags at the ac utility grid will cause over or under voltage faults at the dc microgrid. If the power flows from the dc microgrid to the ac utility grid at the moment of ac grid voltage sags, an overvoltage fault at the dc microgrid will occur. If the power flows from the ac utility grid to the dc microgrid at the moment of ac grid voltage sags, a low-voltage fault at the dc microgrid will occur. Second, the power balance control is more challenging due to heterogeneous sources connected to the $\mathrm{dc}$ bus. It is difficult to coordinate the output power of these sources in a short time. Third, the transient support such as stabilizing dc voltage and supporting reactive power needs to be provided during the FRT.

Focusing on above challenges, this paper proposes a chopperless FRT control strategy for the dc microgrid. First, based on the $d-q$ synchronized frame, a multi-objective control strategy is designed for the BPC to maximize the output reactive power and minimize dc bus voltage ripples under the current limitation. Through the proposed strategy, the BPC can provide bidirectional support for both the dc microgrid and the utility grid during faults. Second, a decentralized emergency power coordinated control strategy among different DGs is adopted to achieve power balance control, which utilizes the controllability of the dc microgrid without using a chopper circuit. Both high- and low-voltage faults of the dc bus can be ridden through. At the same time, the system cost and complexity can be reduced effectively by using the proposed means. The comparison between the proposed control method and the existing control methods is shown in Table I. The effectiveness of the proposed chopperless FRT control strategy is verified through related case studies based on simulations and hardware-in-loop tests.

The remainder of this paper is organized as follows. In Section II, the multiple objective control for the BPC is introduced. In Section III, the decentralized emergency power coordinated control among different DGs is presented. Then, case studies are conducted and discussions are made in Section IV. At last, the conclusions are drawn in Section V.

\section{Multi-ObJective Control For the BPC}

The BPC connects the dc microgrid and utility grid, for exchanging power between the dc network and the ac grid. As shown in Fig.2 (a), on the ac side, the terminal voltages of the 
utility grid are $v\left(v_{a}, v_{b}, v_{c}\right)$, the output ac currents of the BPC are $i\left(i_{a}, i_{b}, i_{c}\right)$ and they are smoothed by the inductive filter $L$. On the dc side, the output dc voltage is $v_{d c}$ and it is smoothed by the capacitive filter $C$, the output dc current is $i_{d c}$, the line resistance is $R_{B P C}$. The overall control for the BPC is shown in Fig.2 (b). In the normal state, the BPC works with the storage and adopts the dc droop control to provide the voltage support for the dc microgrid. While in the fault state, the BPC needs to switch the control strategy and remains in grid-connected mode for a specified period to support the transient stability of the utility grid.

Being different from the conventional distributed generators, when voltage sags of the external utility grid occur, the BPC should achieve following goals:

1) Maintaining the stable dc voltage;

2) Maximizing the output reactive power;

3) Limiting the output currents under maximum values.

Hence, a proper multi-objective control strategy is necessary to generate reference currents for the BPC.

For unbalanced voltages, output instantaneous power of the BPC can be expressed as

$$
\begin{gathered}
S=p+\mathrm{j} q=\left(v^{+}+v^{-}\right) \cdot\left(i^{+}+i^{-}\right)^{*}=\left[\left(v_{d}^{+}+\mathrm{j} v_{q}^{+}\right) e^{\mathrm{j} \omega t}+\right. \\
\left.\left(v_{d}^{-}+\mathrm{j} v_{q}^{-}\right) e^{-\mathrm{j} \omega t}\right] \cdot\left[\left(i_{d}^{+}+\mathrm{j} i_{q}^{+}\right) e^{\mathrm{j} \omega t}+\left(i_{d}^{-}+\mathrm{j} i_{q}^{-}\right) e^{-\mathrm{j} \omega t}\right]^{*} .
\end{gathered}
$$

Eq.(1) can be further expressed as follows:

$$
\begin{array}{cccccc}
P_{0} & v_{d}^{+} & v_{q}^{+} & v_{d}^{-} & v_{q}^{-} & \\
P_{2 c} & v_{d}^{-} & v_{q}^{-} & v_{d}^{+} & v_{q}^{+} & i_{d}^{+} \\
P_{2 s} & v_{q}^{-} & -v_{d}^{-} & -v_{q}^{+} & v_{d}^{+} & i_{q}^{+} \\
Q_{0} & v_{q}^{+} & -v_{d}^{+} & v_{q}^{-} & -v_{d}^{-} & i_{d}^{-} \\
Q_{2 c} & v_{q}^{-} & -v_{d}^{-} & v_{q}^{+} & -v_{d}^{+} & \left\lfloor i_{q}^{-}\right\rfloor
\end{array}
$$

where instantaneous active power $p=P_{0}+P_{2 c} \cdot \cos 2 \omega t+$ $P_{2 s} \cdot \sin 2 \omega t$, instantaneous reactive power $q=Q_{0}+Q_{2 c}$. $\cos 2 \omega t+Q_{2 s} \cdot \sin 2 \omega t . v_{d}^{+}$and $v_{q}^{+}$are components of the positive-sequence volatge $v^{+}$on the positive $d q$ frame, while $v_{d}^{-}$and $v_{q}^{-}$are components of the negative-sequence voltage $v^{-}$on the negative $d q$ frame. The same style of subscription is applied to the currents as $i_{d}^{+}, i_{q}^{+}, i_{d}^{-}$and $i_{q}^{-}$. Their phase relationship is shown in Fig.2 (c) and the detailed flow chart of the sequence extractor is shown in Fig.2 (d).

It can be seen that unbalanced voltage sags will cause the instantaneous power fluctuation at the second harmonic frequency. Furthermore, the instantaneous active power fluctuation will cause dc voltage oscillation. This ripple voltage can be effectively mitigated by suppressing the instantaneous active power fluctuation rather than using large dc capacitors due to its low frequency $(100$ or $120 \mathrm{~Hz})$. Based on (2), the following reference output currents can make $P_{2 c}$ and $P_{2 s}$ equal to zero,

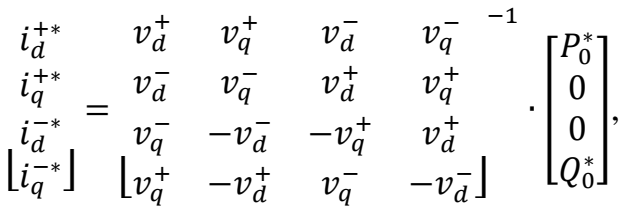

where $i_{d}^{+*}, i_{q}^{+*}, i_{d}^{-*}$ and $i_{q}^{-*}$ are the reference output currents, $P_{0}^{*}$ is the reference active power, $Q_{0}^{*}$ is the reference reactive power.

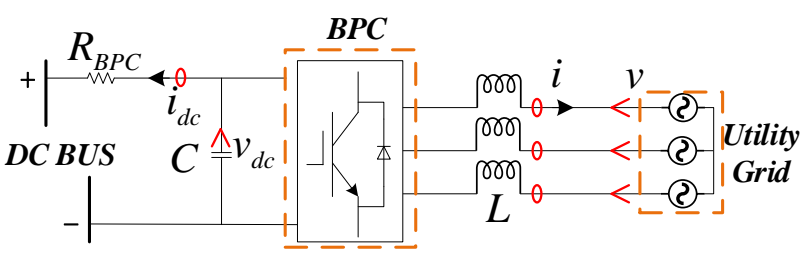

(a)

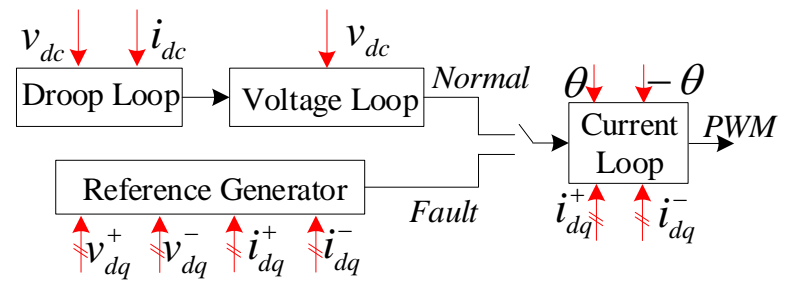

(b)

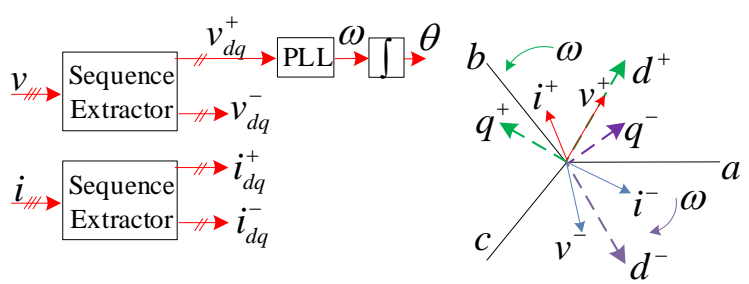

(c)

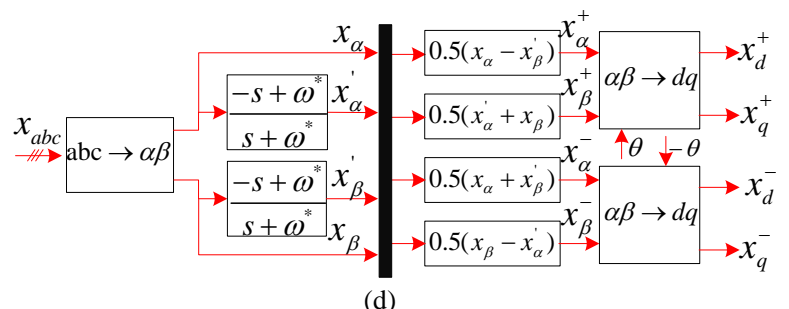

Fig.2. Topology and control of the BPC. (a) Topology. (b) Overall control. (c) Phase relationship between positive and negative sequences. (d) Sequence extractor, where $x=v, i$.

The detailed expanded form of (3) can be derived as

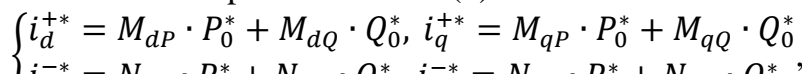

$\left\{i_{d}^{-*}=N_{d P} \cdot P_{0}^{*}+N_{d Q} \cdot Q_{0}^{*}, i_{q}^{-*}=N_{q P} \cdot P_{0}^{*}+N_{q Q} \cdot Q_{0}^{*}\right.$

where $\left|v^{+}\right|^{2}=\left(v_{d}^{+}\right)^{2}+\left(v_{q}^{+}\right)^{2},\left|v^{-}\right|^{2}=\left(v_{d}^{-}\right)^{2}+\left(v_{q}^{-}\right)^{2}$,

$$
\begin{aligned}
& M_{d P}=\frac{2 v_{d}^{+}}{3\left(\left|v^{+}\right|^{2}\left|v^{-}\right|^{2}\right)}, M_{d Q}=\frac{2 v_{q}^{+}}{3\left(\left|v^{+}\right|^{2}+\left|v^{-}\right|^{2}\right)}, \\
& M_{q P}=\frac{2 v_{q}^{+}}{3\left(\left|v^{+}\right|^{2}-\left|v^{-}\right|^{2}\right)}, M_{q Q}=\frac{-2 v_{d}^{+}}{3\left(\left|v^{+}\right|^{2}+\left|v^{-}\right|^{2}\right)}, \\
& N_{d P}=\frac{-2 v_{d}^{-}}{3\left(\left|v^{+}\right|^{2}-\left|v^{-}\right|^{2}\right)}, N_{d Q}=\frac{2 v_{q}^{-}}{3\left(\left|v^{+}\right|^{2}+\left|v^{-}\right|^{2}\right)}, \\
& N_{q P}=\frac{-2 v_{q}^{-}}{3\left(\left|v^{+}\right|^{2}-\left|v^{-}\right|^{2}\right)}, \quad N_{q Q}=\frac{-2 v_{d}^{-}}{3\left(\left|v^{+}\right|^{2}+\left|v^{-}\right|^{2}\right)} .
\end{aligned}
$$

On the other hand, to support the utility grid, the BPC should export as much reactive power as possible. However, the maximum output current of the BPC is limited, hence the following optimization problem is formed

$$
\begin{aligned}
& \max Q_{0}^{*} \\
& \text { s.t. }\left|i_{a}^{*}\right| \leq I_{\text {max }},\left|i_{b}^{*}\right| \leq I_{\text {max }},\left|i_{c}^{*}\right| \leq I_{\text {max }},
\end{aligned}
$$

where $\left|i_{a}^{*}\right|,\left|i_{b}^{*}\right|,\left|i_{c}^{*}\right|$ are the amplitudes of reference currents $i_{a}^{*}, i_{b}^{*}, i_{c}^{*}$ on the $a b c$ frame respectively, $I_{\max }$ is the allowable maximum output current of the BPC.

The positive- and negative-sequence currents and their 
corresponding components are shown in Fig.2 (c). Through their phase relationship, current amplitudes can be derived as

$$
\begin{aligned}
\left|i_{a}^{*}\right| & =\sqrt{\left(i_{d}^{+*}+i_{d}^{-*}\right)^{2}+\left(i_{q}^{-*}-i_{q}^{+*}\right)^{2}} \\
\left|i_{b}^{*}\right| & =\sqrt{\left(\frac{\sqrt{3}}{2} i_{q}^{+*}-\frac{1}{2} i_{d}^{+*}+\frac{\sqrt{3}}{2} i_{q}^{-*}-\frac{1}{2} i_{d}^{-*}\right)^{2}+\left(\frac{\sqrt{3}}{2} i_{d}^{+*}+\frac{1}{2} i_{q}^{+*}-\frac{\sqrt{3}}{2} i_{d}^{-*}-\frac{1}{2} i_{q}^{-*}\right)^{2}} \\
\left(\left|i_{c}^{*}\right|\right. & =\sqrt{\left(\frac{\sqrt{3}}{2} i_{q}^{+*}+\frac{1}{2} i_{d}^{+*}+\frac{\sqrt{3}}{2} i_{q}^{-*}+\frac{1}{2} i_{d}^{-*}\right)^{2}+\left(\frac{\sqrt{3}}{2} i_{d}^{+*}-\frac{1}{2} i_{q}^{+*}-\frac{\sqrt{3}}{2} i_{d}^{-*}+\frac{1}{2} i_{q}^{-*}\right)^{2}}
\end{aligned}
$$

Combining (4) and (6), the optimization problem (5) can be further expressed as

$$
\begin{gathered}
\max Q_{0}^{*} \\
\text { s.t. } \\
\left(A_{1} P_{0}^{*}+A_{2} Q_{0}^{*}\right)^{2}+\left(A_{3} P_{0}^{*}+A_{4} Q_{0}^{*}\right)^{2} \leq I_{\text {max }}^{2} \\
\left(B_{1} P_{0}^{*}+B_{2} Q_{0}^{*}\right)^{2}+\left(B_{3} P_{0}^{*}+B_{4} Q_{0}^{*}\right)^{2} \leq I_{\text {max }}^{2} \\
\left(C_{1} P_{0}^{*}+C_{2} Q_{0}^{*}\right)^{2}+\left(C_{3} P_{0}^{*}+C_{4} Q_{0}^{*}\right)^{2} \leq I_{\text {max }}^{2}
\end{gathered}
$$

where

$$
\begin{gathered}
A_{1}=M_{d P}+N_{d P}, A_{2}=M_{d Q}+N_{d Q}, \\
A_{3}=N_{q P}-M_{q P}, A_{4}=N_{q Q}-M_{q Q}, \\
B_{1}=\frac{\sqrt{3}}{2}\left(M_{q P}+N_{q P}\right)-\frac{1}{2}\left(M_{d P}+N_{d P}\right), \\
B_{2}=\frac{\sqrt{3}}{2}\left(M_{q Q}+N_{q Q}\right)-\frac{1}{2}\left(M_{d Q}+N_{d Q}\right), \\
B_{3}=\frac{\sqrt{3}}{2}\left(M_{d P}-N_{d P}\right)+\frac{1}{2}\left(M_{q P}-N_{q P}\right), \\
B_{4}=\frac{\sqrt{3}}{2}\left(M_{d Q}-N_{d Q}\right)+\frac{1}{2}\left(M_{q Q}-N_{q Q}\right), \\
C_{1}=\frac{\sqrt{3}}{2}\left(M_{q P}+N_{q P}\right)+\frac{1}{2}\left(M_{d P}+N_{d P}\right), \\
C_{2}=\frac{\sqrt{3}}{2}\left(M_{q Q}+N_{q Q}\right)+\frac{1}{2}\left(M_{d Q}+N_{d Q}\right), \\
C_{3}=\frac{\sqrt{3}}{2}\left(M_{d P}-N_{d P}\right)-\frac{1}{2}\left(M_{q P}-N_{q P}\right), \\
C_{4}=\frac{\sqrt{3}}{2}\left(M_{d Q}-N_{d Q}\right)-\frac{1}{2}\left(M_{q Q}-N_{q Q}\right) .
\end{gathered}
$$

From (8)-(10), it can be seen that each constraint forms an elliptical area and the ellipse is not symmetrical to the axes (y-axis for the active power and $\mathrm{x}$-axis for the reactive power) but rotating with respect to the center of a certain angle, depending on the severity of unbalanced voltage sags. The ellipses of constraints listed in (8)-(10) are shown in Fig.3 (a).

It should be noted that some literature considers that $Q_{0}^{*}$ can reach its maximum value when $P_{0}^{*}=0$, i.e., the BPC only outputs the reactive power [5],[20],[30]. However, it is not true for the unbalanced voltage sags because the ellipse is not symmetrically positioned to the active and reactive axes as shown in Fig.3 (b). Therefore, the maximum output reactive power is shifted to a non-zero active power value shown as the point $J$ instead of the point $G$.

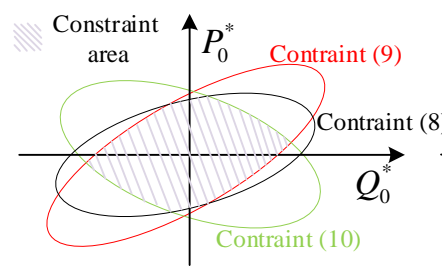

(a)

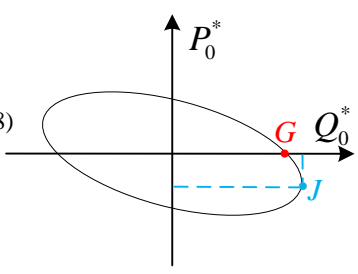

(b)
Fig.3. Constraint area. (a) Single constraint area and final constraint area. (b) Maximum output reactive power.

The optimization of (7)-(10) can be achieved by the geometric method. As shown in Fig.4, let $P_{0}^{*}=k Q_{0}^{*}$, then
$Q_{0,(8)}^{*}, Q_{0,(9)}^{*}$ and $Q_{0,(10)}^{*}$ can be obtained from (8), (9), (10). In this situation, the feasible solution of the optimization problem is the minimum value of these three solutions, namely, $\min \left\{Q_{0,(8)}^{*}, Q_{0,(9)}^{*}, Q_{0,(10)}^{*}\right\}$. Therefore, the optimal solution can be obtained through scanning the slope $k$. Fig.5 shows the corresponding computation flow chart.

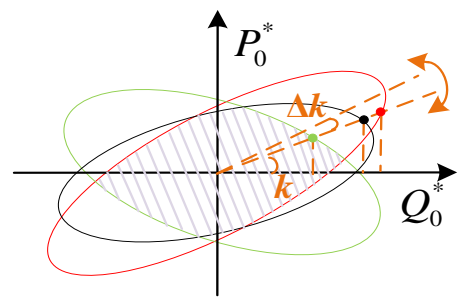

Fig.4. Principle of the slope-scanning method, where $\Delta k$ is the slope change

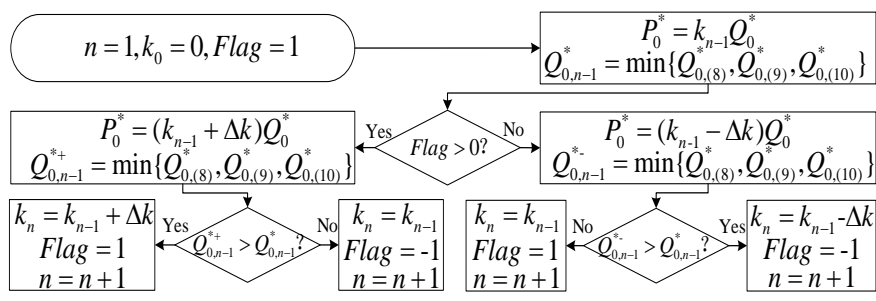

Fig.5. Flow chart of the slope-scanning method.

Based on (7)-(10) and Fig.5, the reference power $P_{0}^{*}$ and $Q_{0}^{*}$ can be obtained. Furthermore, based on (3)-(4), the reference output currents $i_{d}^{+*}, i_{q}^{+*}, i_{d}^{-*}$ and $i_{q}^{-*}$ can be calculated then sent to the current loop of the closed-loop control as shown in Fig.6. Therefore, combining (3)-(4) and (7)-(10), the multi-objective control strategy for the BPC is formed, which can maintain the dc voltage stable, maximize the output reactive power and limit the output currents under maximum values.

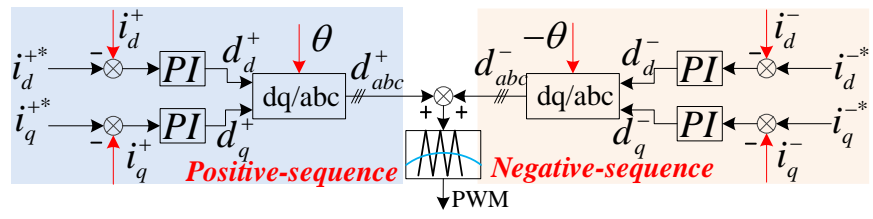

Fig.6. Detailed control block diagram of the current loop.

\section{DECENTRALIZED EMERGENCY POWER COORDINATED CONTROL AMONG DIFFERENT DGS}

This section mainly introduces the decentralized emergency power coordinated control among different DGs inside the dc microgrid to realize the power balance and to avoid the high-voltage as well as the low-voltage faults at the dc bus. Being different from the conventional control for DGs, the proposed control strategy fully utilizes the controllability of the dc microgrid without using the chopper circuit, which can save the system cost and reduce the structure complexity.

The whole emergency power coordinated control is divided into two parts, the control for the storages and the control for the renewable energy sources. The storages are used for voltage support, while the renewable energy sources such as PV generators, wind turbines and so on are controlled for power support. These two parts coordinate with each other through the 
dc bus voltage signal in a decentralized fashion, which can realize the coordinated regulation among different distributed generators in a short time.

\section{A. Control for the Storage}

As shown in Fig.7, the storage consists of the battery and the bidirectional boost $\mathrm{dc} / \mathrm{dc}$ converter. The terminal voltage of the battery is $V_{S}$, the inductive filter is $L_{v}$ and its current is $i_{v}$, the capacitive filter is $C_{v}$ and its voltage (also the output voltage) is $v_{o}$, the output current is $i_{o}$, the line resistance is $R_{v}$.

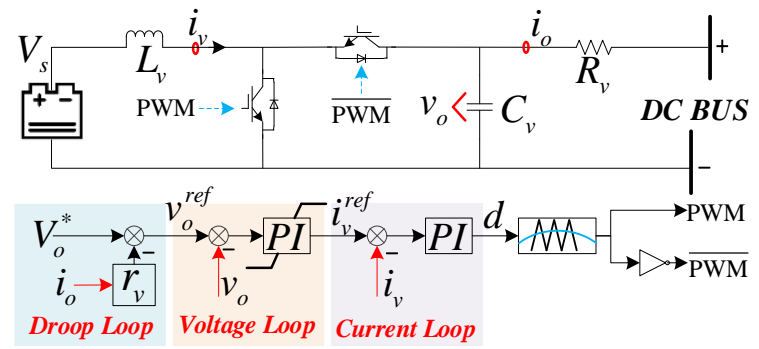

Fig.7. Control strategy for the storage.

The control for the storage is formed by three loops. The outermost loop is the dc droop controller, which coordinates the BPC and the storage to provide the dc bus voltage support for the dc microgrid. For serious voltage sags at the utility grid, the dc bus voltage is mainly supported by the storage. The control law of the dc droop controller can be expressed as

$$
v_{o}^{r e f}=V_{o}^{*}-r_{v} \cdot i_{o},
$$

where $r_{v}$ is the droop coefficient.

The middle loop is the proportional-integral (PI) based voltage controller with amplitude-limiting function. The voltage controller tracks the reference voltage $v_{o}^{r e f}$ and generates reference current for the innermost loop. The control law of the voltage controller can be expressed as

$$
i_{v}^{r e f}= \begin{cases}I_{v}^{\max }, & i_{P I}>I_{v}^{\max } \\ i_{P I}, & -I_{v}^{\max } \leq i_{P I} \leq I_{v}^{\max }, \\ -I_{v}^{\text {max }}, & i_{P I} \leq-I_{v}^{\text {max }}\end{cases}
$$

where $I_{v}^{\max }$ is the maximum charging and discharging current of the battery, $i_{P I}$ is the output of the PI controller.

The innermost loop is the PI based current controller, which can realize flexible regulation of the charging and discharging current of the battery. At the same time, combining (12), the controller can protect the battery from the overcurrent fault.

The power exchange between the dc microgrid and the utility grid must be greatly limited when serious voltage sags occur at the utility grid. If the dc microgrid releases power to the utility as normal operation, the system power will be surplus in the fault state. While the dc microgrid absorbs power from the utility grid as normal operation, the system power will be insufficient in the fault state. The droop control will regulate the dc bus voltage into the high-voltage (HV) or low-voltage (LV) region by using the fast control and bidirectional power flow abilities of the storage. Then, other slow and unidirectional renewable energy sources such as PV generators can perceive the changes of the dc bus voltage and increase or decrease output power correspondingly as shown in Fig.8, which can further balance the system power and maintain the system stability.

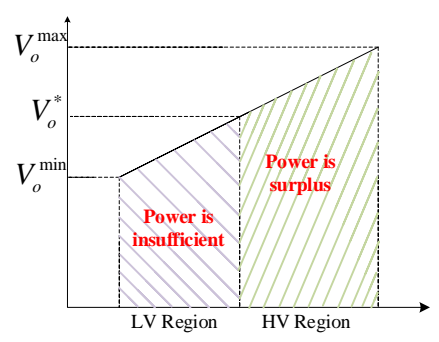

Fig.8. Dc bus voltage signal.

\section{B. Control for Renewable Energy Sources}

Since the proposed control method does not depend on the chopper circuit to balance the system power, the renewable energy sources are required to respond the power changes to increase the system regulation ability and to alleviate the burden of the storage. Without loss of generality, taking PV generators as an example, the emergency power coordinated control for the renewable energy sources is introduced in this part.

As shown in Fig.9, the PV panel is connected to the dc bus through a DC/DC converter. On the output side, the LCL filter is used to smooth the current. Its inductors are $L_{1}, L_{2}$ and capacitor is $C_{c}$, the corresponding output current and the capacitive current are $i_{2}$ and $i_{c}$ respectively. On the input side, the capacitive filter is $C_{p v}$, the output voltage and the current of the PV panel are $v_{p v}$ and $i_{p v}$ respectively. The line resistance between the PV generator and the dc bus is $R_{p v}$, the dc bus voltage is $v_{b}$.

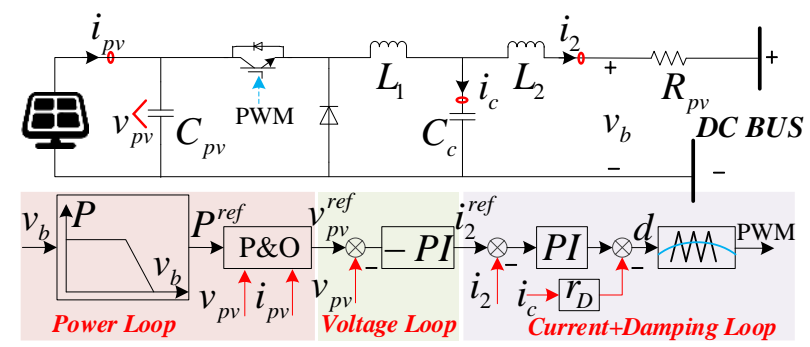

Fig.9. Control strategy for the PV generator.

The control strategy for the PV generator consists of three loops. The outermost loop is the power controller, which regulates output power according to changes of the dc bus voltage $v_{b}$. The middle loop is the PI based voltage controller, which tracks the reference voltage accurately and generates reference current for the innermost loop. The innermost loop is the combination of the current controller and the active damping controller, which can regulate the output current of the LCL filter and can enhance system damping to avoid LC resonance.

The power controller of the PV generator is the key to realize the chopperless FRT operation, which includes defining the power reference and regulating the output power to follow the reference. As analyzed in Part A, if the dc bus voltage $v_{b}$ is in the HV region, the system power is surplus, hence the PV generator should limit its output power. While if the dc bus voltage $v_{b}$ is in the $\mathrm{LV}$ region, the system power is insufficient, hence the PV generator should enhance its output power. The principle of reference power generation is shown in Fig.10 (a) 
and the corresponding control law can be expressed as

$$
P_{j}^{r e f}= \begin{cases}P_{j}^{*}, & v_{b}<V_{b}^{*} \\ r_{j}\left(V_{b}^{\text {max }}-v_{b}\right), & V_{b}^{*} \leq v_{b} \leq V_{b}^{\text {max }}, \\ 0, & v_{b}>V_{b}^{\text {max }}\end{cases}
$$

where $j$ means the $j$-th $\mathrm{PV}$ generator, $P_{j}^{\text {ref }}$ is the reference power, $P_{j}^{*}$ is the maximum output power of the $\mathrm{PV}$ generator and equals to the rated power of the DC/DC converter, $V_{b}^{*}$ is the rated dc bus voltage, $V_{b}^{\max }$ is the allowable maximum dc bus voltage, $r_{j}$ is the regulation coefficient of limiting power.

According to the capacities of different PV generators, the regulation coefficient $r_{j}$ can be set as

$$
r_{j}=P_{j}^{*} /\left(V_{b}^{\max }-V_{b}^{*}\right) .
$$

Based on (14), it can be seen that different PV generators can limit their output power in coordination.

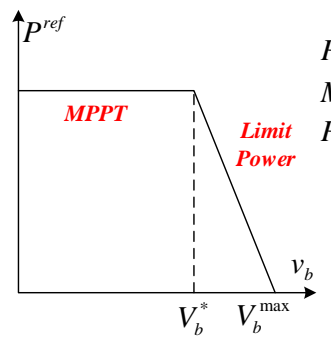

(a)

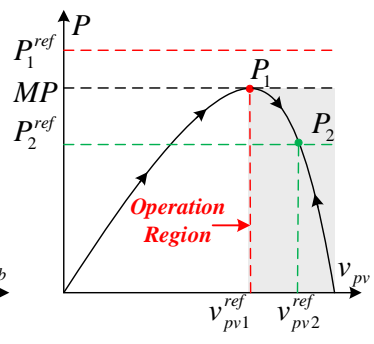

(b)
Fig.10. Power controller of the PV generator. (a) Principle of reference power generation. (b) Principle of modified $\mathrm{P} \& \mathrm{O}$ based power regulation.

$$
\left.\begin{array}{c}
\text { Sample } \\
v_{p v}(n), i_{p v}(n), P^{r e f}
\end{array} \begin{array}{c}
P(n)=v_{p v}(n) \cdot i_{p v}(n) \\
\Delta P=P(n)-P(n-1) \\
\Delta v_{p v}=v_{p v}(n)-v_{p v}(n-1)
\end{array}\right]
$$

Fig.11.Flow chart of the modified $\mathrm{P} \& \mathrm{O}$ based power regulation, where $\varepsilon$ is the perturbation size.

For the power regulation, the modified perturbation and observation ( $\mathrm{P} \& \mathrm{O})$ method is adopted and the flow chart is shown in Fig.11. First, the right side of the PV voltage-power curve is chosen as the operation region to enhance the system stability because the system stable margin on the right side is relatively larger than the left side[31]-[32]. Next, when the reference of the output power is less than the maximum power (MP) of the PV generator, the power regulator makes the PV generator output the specified reference output power as the operation point $P_{2}$ in Fig.10 (b), where $P_{2}^{r e f}<M P$. If the reference of the output power is more than the MP of the PV generator, the power regulator just makes the PV generator output the MP. This process is similar to the maximum power point tracking (MPPT) mode as the operation point $P_{1}$ in Fig.10 (b), where $P_{1}^{r e f}>M P$.

\section{CASE STUdies}

To verify the effectiveness of the proposed chopperless FRT control for the dc microgrid, a dc microgrid system containing multiple sources has been studied, whose system architecture is similar to Fig.1 (a). There are three PV generators to provide power support, while one storage and one BPC to maintain the dc bus voltage. Simulation and hardware-in-loop results are provided for FRT case studies. The hardware-in-loop (HIL) tests are based on the RTLAB and STM32F407 MCUs as shown in Fig.12, where the main loop is conducted in the RTLAB and the algorithm of the proposed chopperless FRT control is realized through the STM32F407 MCUs.

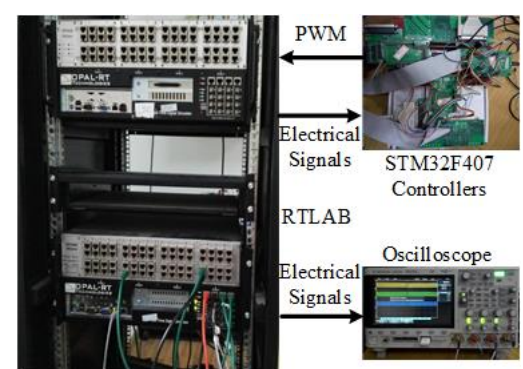

Fig.12. HIL tests setup.

\begin{tabular}{|c|c|c|c|}
\hline \multirow{2}{*}{ Parameters } & \multicolumn{3}{|c|}{ Rated Value } \\
\hline & PV1 & PV2 & PV3 \\
\hline $\begin{array}{l}\text { Filters }\left(C_{p v}, L_{1}, C_{c} L_{2}\right) \\
\text { Irradiance \&Temperature }\end{array}$ & \multicolumn{3}{|c|}{$1 \mathrm{mF}, 1.8 \mathrm{mH}, 20 \mu \mathrm{F}, 0.9 \mathrm{mH}$} \\
\hline Line Resistance $\left(R_{p v}\right)$ & $15 \mathrm{~m} \Omega$ & $10 \mathrm{~m} \Omega$ & $10 \mathrm{~m} \Omega$ \\
\hline Maximum Power $\left(P_{j}^{*}\right)$ & $45 \mathrm{~kW}$ & $60 \mathrm{~kW}$ & $70 \mathrm{~kW}$ \\
\hline Regulating Coefficient $\left(r_{j}\right)$ & $643 \mathrm{~W} / \mathrm{V}$ & $857 \mathrm{~W} / \mathrm{V}$ & $1000 \mathrm{~W} / \mathrm{V}$ \\
\hline Perturbation Size & \multicolumn{3}{|c|}{$\varepsilon=0.1 \mathrm{~V}$} \\
\hline Voltage Loop (PI) & \multicolumn{3}{|c|}{$k_{P}=2, k_{I}=100$} \\
\hline Current Loop (PI) & \multicolumn{3}{|c|}{$k_{P}=0.012, k_{I}=5$} \\
\hline Damping Loop $(\mathrm{P})$ & \multicolumn{3}{|c|}{$r_{D}=0.01$} \\
\hline \multicolumn{4}{|c|}{ TABLE III } \\
\hline Parameters & \multicolumn{3}{|c|}{ Rated Value } \\
\hline Filters $\left(L_{v}, C_{v}\right)$ & \multicolumn{3}{|c|}{$3 \mathrm{mH}, 5 \mathrm{mF}$} \\
\hline Line Resistance $\left(R_{v}\right)$ & \multicolumn{3}{|c|}{$20 \mathrm{~m} \Omega$} \\
\hline Battery Voltage $\left(V_{s}\right)$ & \multicolumn{3}{|c|}{$400 \mathrm{~V}$} \\
\hline Maximum Current $\left(I_{v}^{\max }\right)$ & \multicolumn{3}{|c|}{$200 \mathrm{~A}$} \\
\hline Reference Voltage $\left(V_{o}^{*}\right)$ & \multicolumn{3}{|c|}{$700 \mathrm{~V}$} \\
\hline Droop Loop $\left(r_{v}\right)$ & \multicolumn{3}{|c|}{$0.8 \mathrm{~V} / \mathrm{A}$} \\
\hline Voltage Loop (PI) & \multicolumn{3}{|c|}{$k_{P}=1.5, k_{I}=200$} \\
\hline Current Loop (PI) & \multicolumn{3}{|c|}{$k_{P}=0.018, k_{I}=2$} \\
\hline \multicolumn{4}{|c|}{ TABLE IV } \\
\hline \multicolumn{4}{|c|}{ PARAMETERS OF THE BPC } \\
\hline Parameters & \multicolumn{3}{|c|}{ Rated Value } \\
\hline Filters $(C, L)$ & \multicolumn{3}{|c|}{$5 \mathrm{mF}, 2.5 \mathrm{mH}$} \\
\hline Line Resistance $\left(R_{B P C}\right)$ & \multicolumn{3}{|c|}{$10 \mathrm{~m} \Omega$} \\
\hline Maximum Current $\left(I_{\max }\right)$ & \multicolumn{3}{|c|}{$200 \mathrm{~A}$} \\
\hline Droop Loop $\left(r_{B P C}\right)$ & \multicolumn{3}{|c|}{$0.4 \mathrm{~V} / \mathrm{A}$} \\
\hline Voltage Loop (PI) & \multicolumn{3}{|c|}{$k_{P}=0.5, k_{I}=60$} \\
\hline PLL (PI) & \multirow{2}{*}{\multicolumn{3}{|c|}{$\begin{array}{l}k_{P}=0.45, k_{I}=8 \\
k_{P}=0.03, k_{I}=1\end{array}$}} \\
\hline Current Loop (PI) & \multirow{2}{*}{\multicolumn{3}{|c|}{$\begin{array}{c}k_{P}=0.03, k_{I}=1 \\
\Delta k=0.1\end{array}$}} \\
\hline Slope Change & & & \\
\hline
\end{tabular}

TABLE II

PARAMETERS OF PV GENERATORS

The rated dc bus voltage is $700 \mathrm{~V}$ and its allowable change range is $[630 \mathrm{~V}, 770 \mathrm{~V}]$ (namely $\pm 10 \%$ ), the rated load power is $70 \mathrm{~kW}$, and the rated utility gird voltage is $311 \mathrm{~V} / 50 \mathrm{~Hz}$. Other detailed parameters about the PV generators, storage and BPC are shown in Table II, Table III and Table IV, respectively. 
In this paper, both asymmetrical and symmetrical faults are studied. Fig.13 (a) shows the asymmetrical fault, where voltage of phase A decreases to 0.1 p.u. while phase $\mathrm{B}$ is simultaneously shifted $\pi / 2$ ahead. Fig. 13 (b) shows the symmetrical fault, where all the three-phase voltages decrease to 0.1 p.u.

Without the FRT control, the dc bus will suffer the high-voltage fault when the microgrid releases power to the utility grid at pre-fault as shown in Fig.13 (c), where the dc bus voltage can exceed $1000 \mathrm{~V}$. The dc bus will suffer the low-voltage fault when the microgrid absorbs power from the utility grid at pre-fault as shown in Fig.13 (d), where the dc bus voltage can be lower than $550 \mathrm{~V}$. These high- and low-voltage faults at the dc bus will cause tripping of connected devices and undermine the system reliability. Therefore, it can be concluded that being different from conventional DGs, voltage sags at the utility grid will trigger both the low- and high-voltage faults of the de microgrid depending on the power direction.

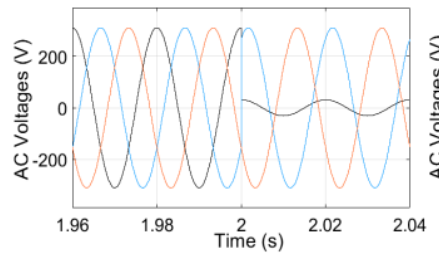

(a)

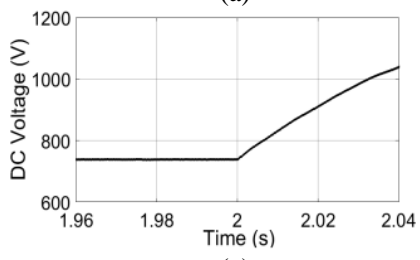

(c)

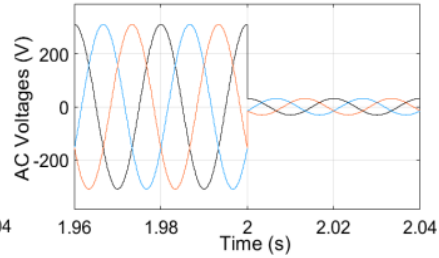

(b)

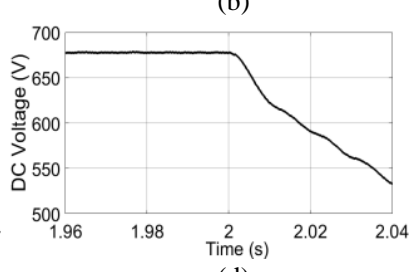

(d)
Fig.13. Changes of ac and dc voltages. (a) Asymmetrical voltage sags. (b) Symmetrical voltage sags. (c) Dc bus high-voltage fault when the microgrid exports power at pre-fault. (d) Dc bus low-voltage fault when the microgrid absorbs power at pre-fault.

\section{A. Simulation Results}

Fig.14 shows the control effects of the proposed chopperless FRT control under the asymmetrical fault. The voltage profile is shown in Fig.13 (a), the fault occurs at $2.0 \mathrm{~s}$ and is cleared at $2.5 \mathrm{~s}$. After fault clearance, the BPC is set to take $0.5 \mathrm{~s}$ to recover to the pre-fault state gradually. The gradual recovery control is as follow

$$
\left\{\begin{array}{l}
P_{0}^{*}=P_{F}^{\prime}+\frac{P_{N}^{\prime}-P_{F}^{\prime}}{T} \Delta t \\
Q_{0}^{*}=Q_{F}^{\prime}+\frac{Q_{N}^{\prime}-Q_{F}^{\prime}}{T} \Delta t
\end{array}\right.
$$

where $P_{N}^{\prime}$ and $Q_{N}^{\prime}$ are the active and reactive power at pre-fault, $P_{F}^{\prime}$ and $Q_{F}^{\prime}$ are the active and reactive power before the fault is cleared, $T$ is the recovery time and it is set as $0.5 \mathrm{~s}$ in this paper. The droop loop and voltage loop of the BPC restart to operate once the active and reactive power reach the pre-fault level.

Fig.14 (a) shows the responses of the BPC, where the positive direction of the output power is from the BPC to the utility grid. It can be seen that the proposed multi-objective control for the BPC can limit output currents below the maximum value $I_{\max }=100 \mathrm{~A}$ and can maximize the output reactive current (also the reactive power). The mean value of the reactive power $Q_{0}$ can reach about $26.7 \mathrm{kVar}$. The oscillation of the output active power is suppressed effectively, which can avoid the oscillation of the dc bus voltage and maintain its stability. From (2), it can be seen that asymmetric faults will result in instantaneous power fluctuation at the second harmonic frequency. Furthermore, the active power and reactive power cannot be controlled at the same time, since there are only four independent variables but six dependent variables in (2). Hence, the oscillation of the output reactive power is inevitable as shown in the figure. The instantaneous reactive power oscillates at the second harmonic frequency namely $100 \mathrm{~Hz}$, and the oscillation amplitude reaches $18 \mathrm{kVar}$. After the fault is cleared, currents, active power and reactive power all recover to their pre-fault values gradually without overshoot due to the graduate recovery control scheme shown in (15).

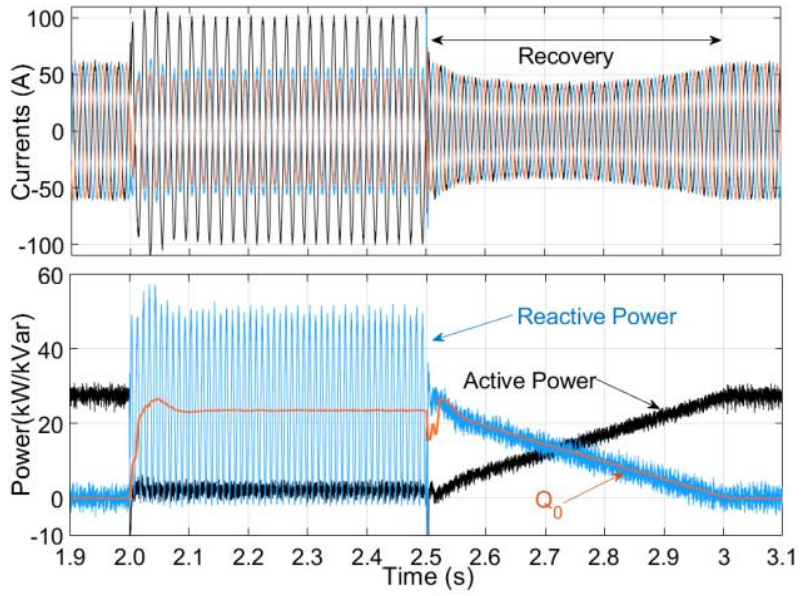

(a)

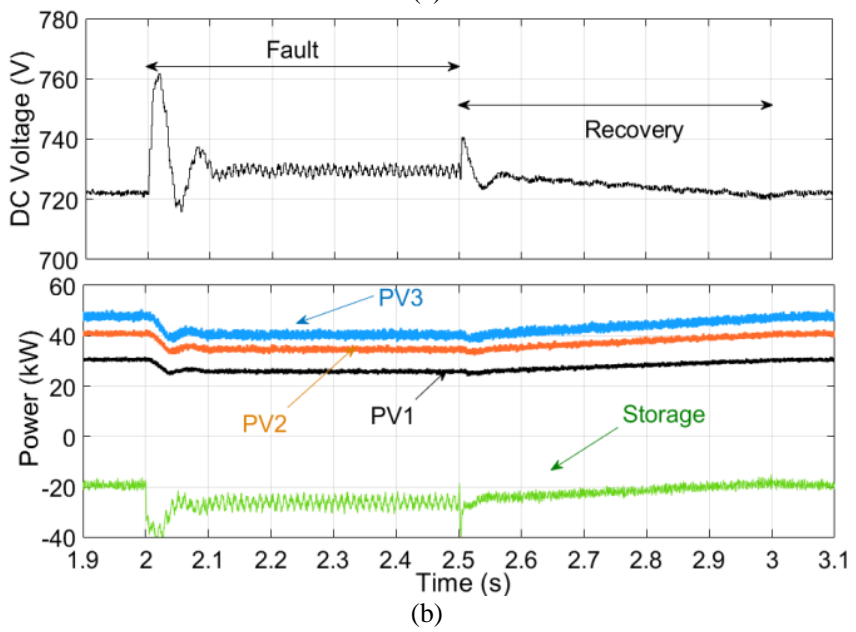

Fig.14. System responses under the chopperless FRT control when the asymmetrical fault occurs. (a) Responses of the BPC. (b) Responses of the dc microgrid.

Fig.14 (b) shows the responses of the distributed generators in the dc microgrid, where the positive direction of the output power is from the distributed generators to the microgrid. First, it can be seen that the dc bus voltage can be kept stable and 
there is no obvious oscillation by applying coordination between the BPC and the storage. Second, the PV generators can decrease their output power in a coordinated way according to their own capacities when the fault occurs, specifically, PV1 decreases about $7 \mathrm{~kW}, \mathrm{PV} 2$ decreases about $9 \mathrm{~kW}$ and PV3 decreases about $11 \mathrm{~kW}$. The coordinated power control alleviates the burden of the storage to absorb excessive power during the fault for protecting the dc bus from overvoltage. These results show that the storage and PV generators can work well under the proposed decentralized emergency power coordinated control. In addition, both the storage and PV generators can regulate their output power to the normal values gradually after the fault is cleared, which avoids oscillation of the dc bus voltage during the recovery period.

Fig. 15 shows the responses of the dc microgrid under the conventional MPPT control without applying the decentralized emergency power coordinated control, while other conditions are the same as those in Fig.14. Compared to Fig.14, it can be seen that PV generators keep the MPPT mode and do not decrease their output power without using the decentralized emergency power coordination control. Then, the burden of power balance is all shifted to the storage, resulting in nearly 90 $\mathrm{kW}$ charging power to the storage. Hence, the absorbing power of the storage is saturated. Also, the dc bus voltage cannot be maintained within the allowable range and it exceeds $1000 \mathrm{~V}$.

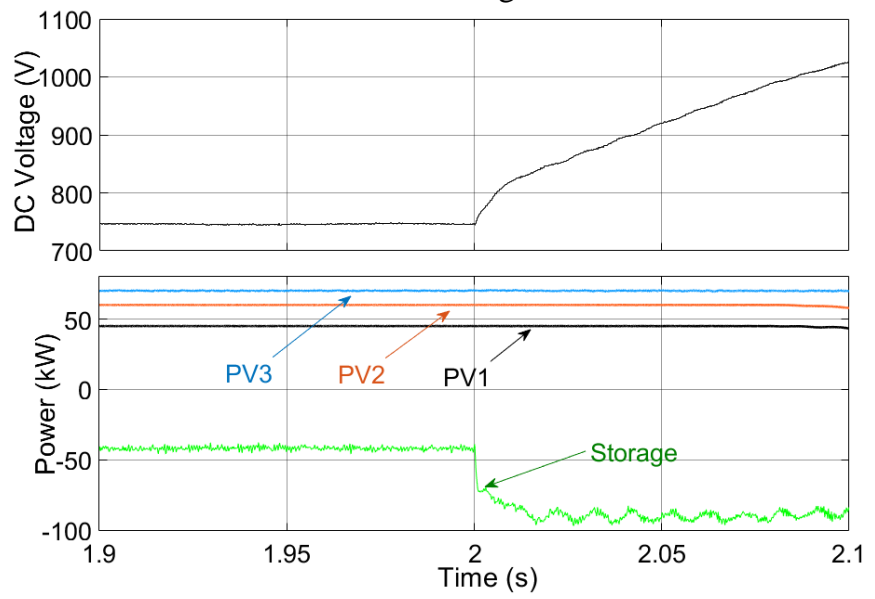

Fig.15. Responses of the dc microgrid under the conventional MPPT control.

To further verify the effectiveness of the proposed chopperless FRT control, the case of three-phase voltage sags is studied. The voltage profile is shown in Fig.13 (b), the fault occurs at $2.0 \mathrm{~s}$ and is cleared at $2.5 \mathrm{~s}$. Similar to Fig.14, the BPC is set to take $0.5 \mathrm{~s}$ to recover to the pre-fault state gradually and the gradual control law is same to (15).

Fig.16 (a) shows the responses of the BPC, where the positive direction of the output power is also from the BPC to the utility grid. It can be seen that the proposed multi-objective control for the BPC can protect it from overcurrent. Since the three-phase voltages are symmetrical during the fault, there are no oscillations of active and reactive power. The maximum reactive currents are generated to support the utility grid, although the reactive power of the BPC is less than asymmetrical FRT shown in Fig.14 (a) because of the lower voltage caused by the three-phase voltage sags. Furthermore, after the fault is cleared, currents, active power and reactive power all recover to their pre-fault values gradually.

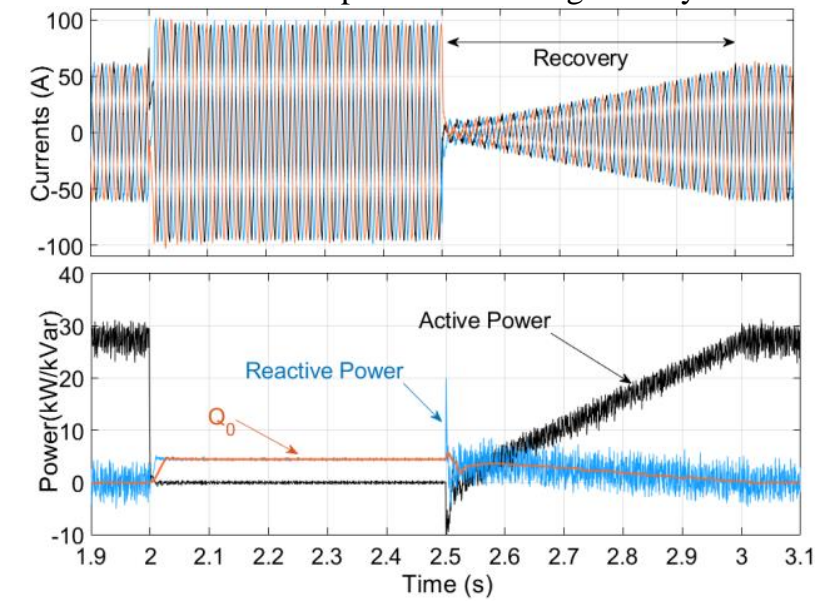

(a)

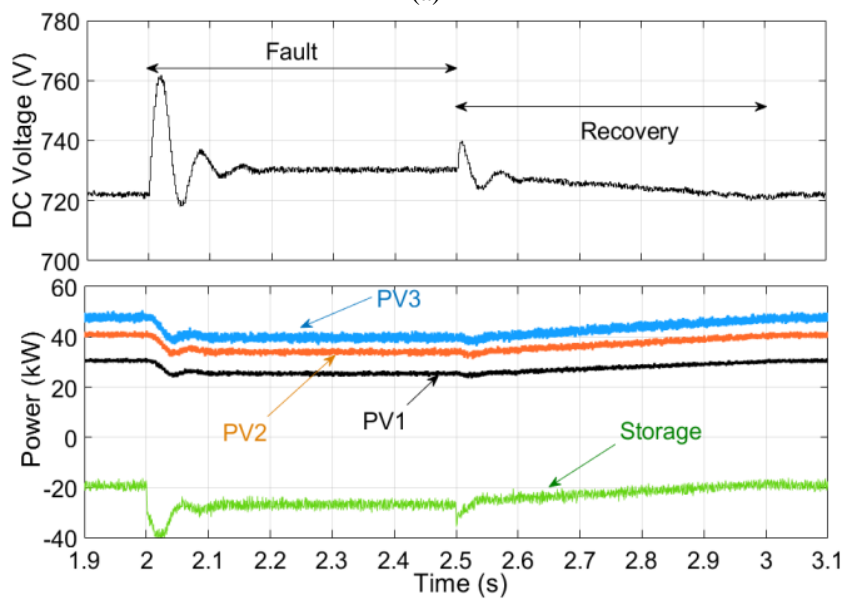

(b)

Fig.16. System responses under the chopperless FRT control when the three-phase voltage sags occur. (a) Responses of the BPC. (b) Responses of the de microgrid.

Fig.16 (b) shows the responses of the distributed generators in the dc microgrid, where the positive direction of the output power is from the distributed generators to the microgrid. It can be seen that the coordination control stabilizes the dc bus voltage without oscillation during the fault. PV generators can decrease their output power in a coordinated way according to their own capacities to avoid overcharging the storage. Compared to Fig.14 (b), minor oscillations of dc bus voltage and storage power do not exist because the fault is symmetrical. From Fig. 14 and Fig.16, it can be concluded that the proposed control strategy can assist the dc microgrid to ride through the both the asymmetrical and symmetrical voltage sags at the ac utility grid in different pre-fault conditions.

\section{B. HIL Results}

Fig.17 shows the HIL results of the proposed chopperless FRT control under the asymmetrical fault, whose voltage profile is shown in Fig.13 (a). The whole FRT has experienced four stages, normal stage $\rightarrow$ fault stage $\rightarrow$ recovery stage $\rightarrow$ normal stage.

Fig.17 (a) shows three-phase currents of the BPC. It can be seen that during the fault interval, the proposed multi-objective 
control can maintain the output currents within the allowable range. Through the detailed changes of currents, it can be found that there is obvious phase shift of the B-phase current after the fault occurs, which is caused by the phase shift of the B-phase voltage as shown in Fig.13 (a). Fig.17 (b) shows the active power and reactive power of the BPC. Similar to the simulation results, the proposed multi-objective control can maximize the output reactive power and suppress the oscillation of the output active power effectively. However, the oscillation of the output reactive power is obvious. Due to the asymmetrical fault, the maximum reactive power generation is achieved when the active power is at a non-zero value as shown in Fig. 3 (b). Hence, during the fault period, the active power is slightly lower than zero. After the fault is cleared, currents, active power and reactive power all recover to their normal values at a slope to ensure stability.

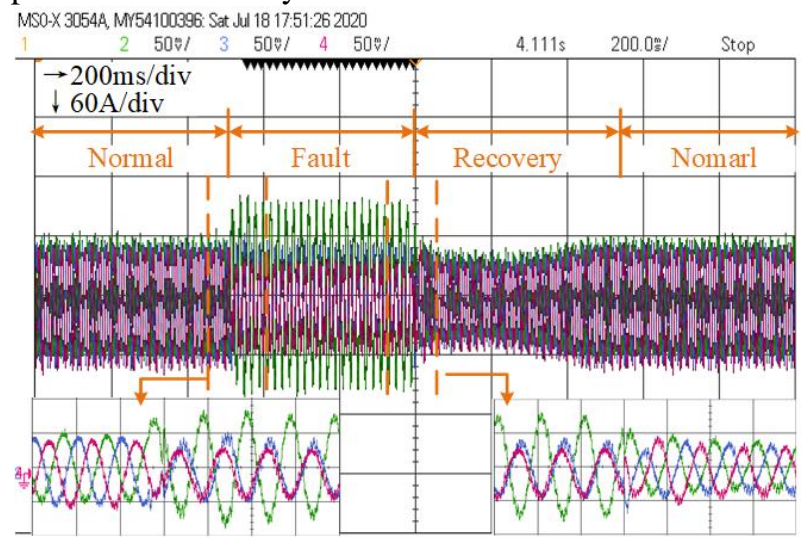

(a)

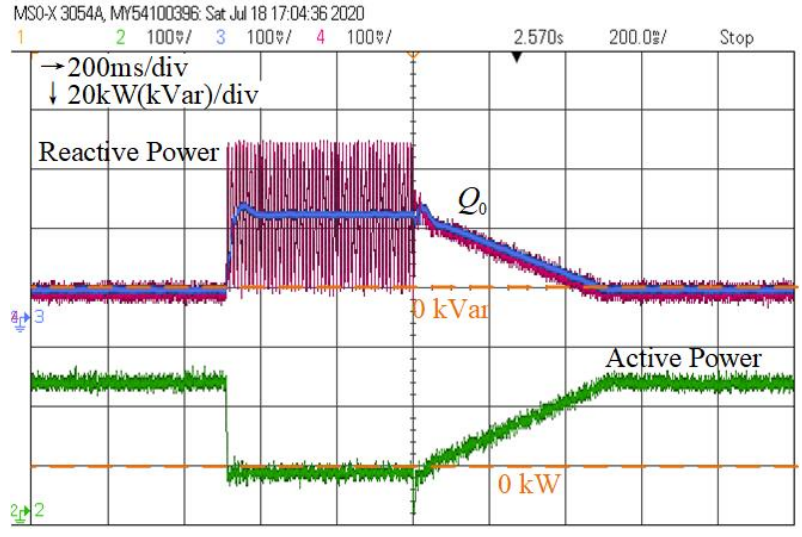

(b)

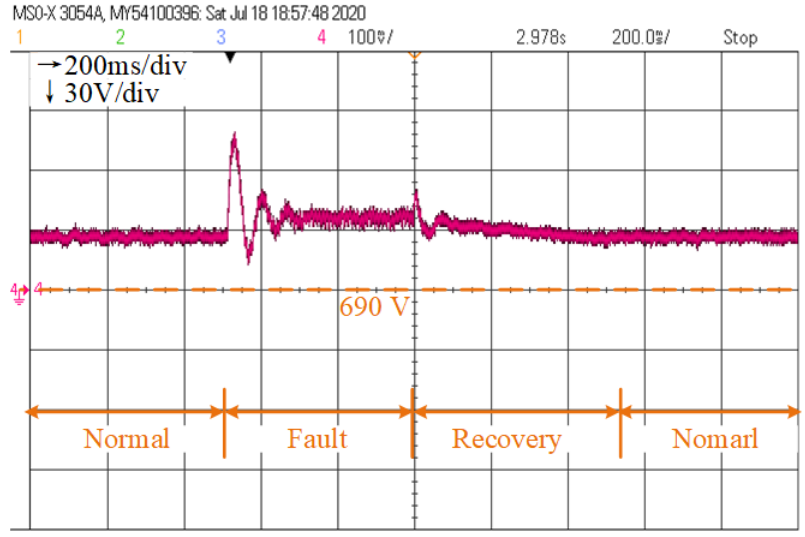

(c)

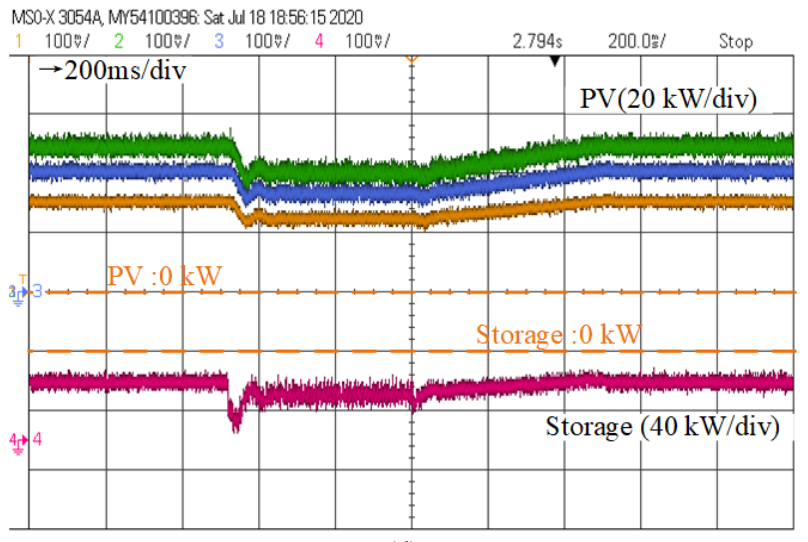

(d)

Fig.17. HIL results of the chopperless FRT control under the asymmetrical fault. (a) Three-phase currents of BPC. (b) Power of BPC. (c) Dc bus voltage. (d) Power of distributed generators.

Fig.17 (c) and (d) show the responses of the distributed generators in the dc microgrid. From Fig.17 (c), it can be seen that the dc bus voltage has been limited to $730 \mathrm{~V}$ despite a $40 \mathrm{~V}$ overshoot at the moment when the fault occurs but no large oscillation. This shows that the coordination among the BPC, the PV generators and the storage is effective to control the voltage to ride through the fault. From Fig.17 (d), it can be found that the PV generators can decrease their output power in a coordinated way according to their own capacities during the fault, which maintains the dc bus voltage within its allowable range. These results show that the storage and PV generators can work well under the proposed decentralized emergency power coordinated control. Both the storage and PV generators can regulate their output power to the normal values gradually after the fault is cleared. The HIL results shown in Fig 17 well match the simulation results shown in Fig 16 and further validate the effectiveness of the proposed control.

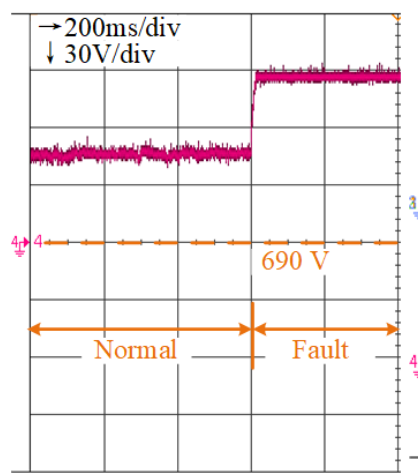

(a)

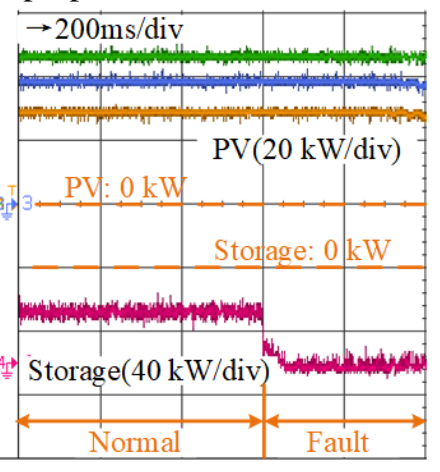

(b)
Fig.18. HIL results of the conventional MPPT control under the asymmetrical fault. (a) Dc bus voltage. (b) Power of distributed generators.

Fig. 18 shows the HIL results of the dc microgrid under the conventional MPPT control without the decentralized emergency power coordinated control, the other conditions are kept the same as those in Fig.17. From Fig.18 (b), it can be seen that the PV generators do not response the changes of dc bus voltage and still keep the pre-fault MPPT mode after the fault occurs. Then, excessive power has overcharged the storage. Therefore, the dc bus voltage cannot be maintained within the 
allowable range. As shown in Fig.18 (a), the dc bus voltage profile is curtailed because it has exceeded the measurable range.

Fig.19 shows the HIL results of the proposed chopperless FRT control under a symmetrical three-phase voltage sags, whose voltage profile is shown in Fig.13 (b). The whole process is also divided into four intervals, normal stage $\rightarrow$ fault stage $\rightarrow$ recovery stage $\rightarrow$ normal stage.

Fig.19 (a) and (b) show the three-phase currents and the active and reactive power of the BPC. First, the output currents can be maintained below the maximum value $I_{\max }=100 \mathrm{~A}$ and the maximum reactive currents are generated. Then, the output reactive power can be maximized, but lower than the value of asymmetrical fault ride-through shown in Fig.17 (b) due to the symmetrically low voltage although the maximum reactive currents have been exported to the utility grid. After the fault is cleared, currents, active power and reactive power all recover to their normal values gradually. The HIL results are close to those in Fig.16 (a), further validating the proposed control scheme.

Fig.19 (c) and (d) show the dc link voltage and the responses of the distributed generators in the dc microgrid, respectively. Being similar to Fig.16 (b), at the fault occurrence, the PV generators can response the dc bus voltage changes and decrease their output power to prevent dc link from overvoltage. Through the coordination with the storage, the dc bus voltage is kept within the allowable range, albeit an approximately $50 \mathrm{~V}$ overshoot at the fault occurrence. After the fault is cleared, PV generators have recovered to their normal states gradually to avoid oscillation of the dc bus voltage.

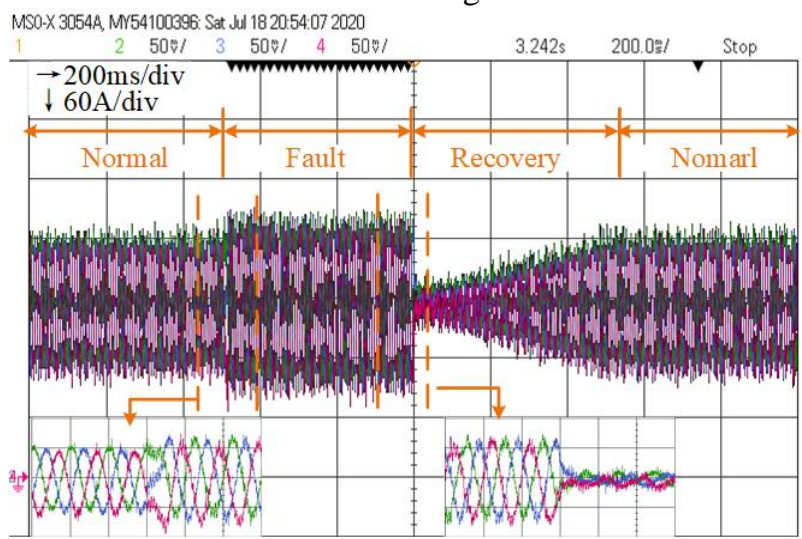

(a)

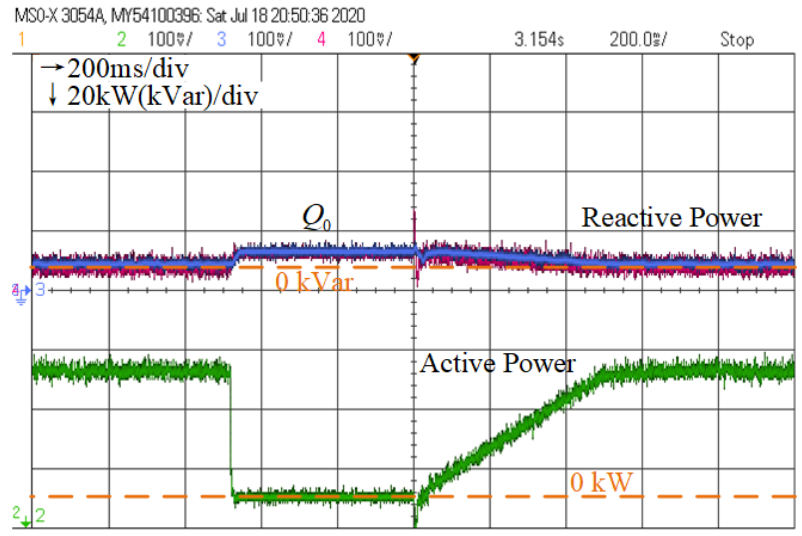

(b)

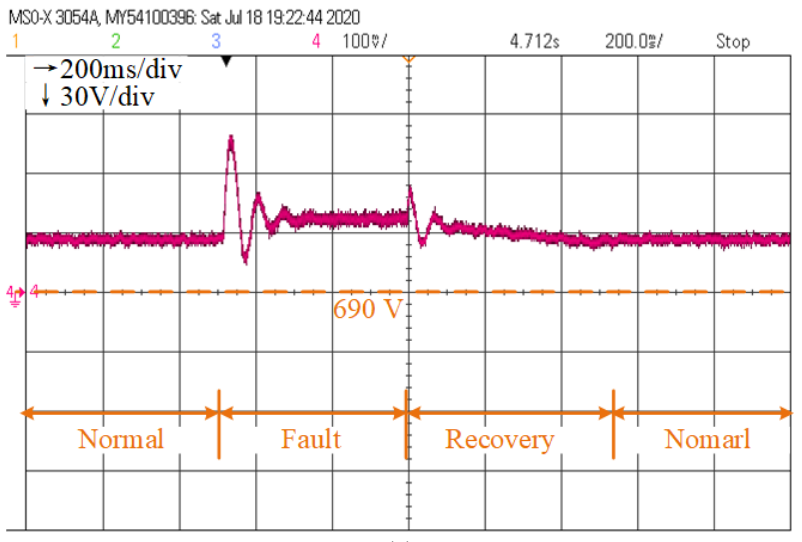

(c)

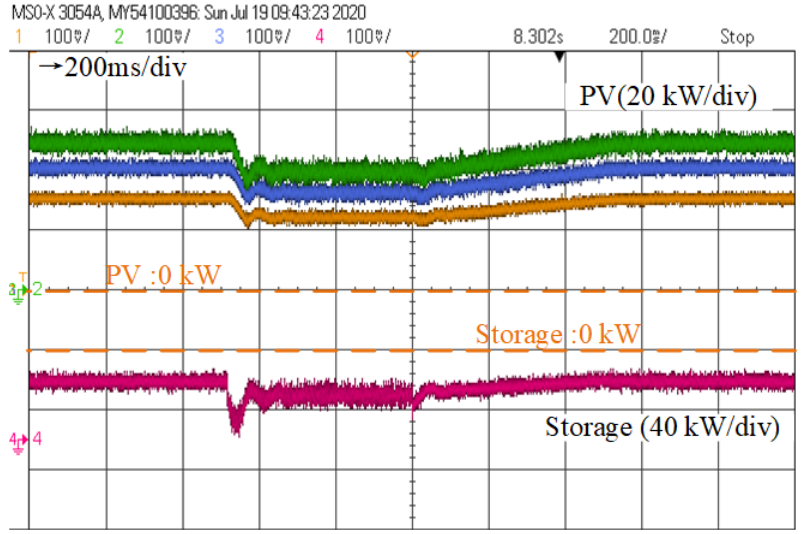

(d)

Fig.19. HIL results of the chopperless FRT control under the three-phase voltage sags. (a) Three-phase currents of BPC. (b) Power of BPC. (c) Dc bus voltage. (d) Power of distributed generators.

\section{CONCLUSION}

This paper reports a chopperless FRT control strategy for dc microgrids. First, the differences between the conventional FRT of distributed generators and the FRT of dc microgrids are explained. Then, a multi-objective control strategy based on the $d-q$ synchronized frame is designed for the BPC to maximize output reactive power and minimize dc bus voltage ripples under the maximum current limitation. The bidirectional support for both the dc microgrids and the utility grid can be provided during faults. Furthermore, a decentralized emergency power coordinated control strategy among different distributed generators is adopted to realize the power balance control, which utilizes the controllability of dc microgrids without using a chopper circuit to reduce the system cost and complexity. Finally, the simulation and HIL results of case studies fully show the effectiveness of the proposed chopperless FRT control strategy.

\section{REFERENCES}

[1] L. E. Zubieta, "Are Microgrids the Future of Energy?: DC Microgrids from Concept to Demonstration to Deployment," IEEE Electrification Magaz., vol. 4, no. 2, pp. 37-44, June 2016.

[2] M. Nasir, H. A. Khan, N. A. Zaffar, J. C. Vasquez and J. M. Guerrero, "Scalable Solar dc Micrigrids: On the Path to Revolutionizing the Electrification Architecture of Developing Communities," IEEE Electrification Magaz., vol. 6, no. 4, pp. 63-72, Dec. 2018.

[3] T. Dragičević, X. Lu, J. C. Vasquez and J. M. Guerrero, "DC Microgrids-Part II: A Review of Power Architectures, Applications, and 
Standardization Issues," IEEE Trans. Power Electron., vol. 31, no. 5, pp. 3528-3549, May 2016.

[4] YS. Alepuz et al., "Control Strategies Based on Symmetrical Components for Grid-Connected Converters Under Voltage Dips," IEEE Trans. Ind. Electron., vol. 56, no. 6, pp. 2162-2173, June 2009.

[5] A. Milicua, G. Abad and M. Á. Rodríguez Vidal, "Online Reference Limitation Method of Shunt-Connected Converters to the Grid to Avoid Exceeding Voltage and Current Limits Under Unbalanced Operation -Part I: Theory," IEEE Trans. Energy Convers., vol. 30, no. 3, pp. 852-863, Sept. 2015.

[6] K. Ma, W. Chen, M. Liserre and F. Blaabjerg, "Power Controllability of a Three-Phase Converter With an Unbalanced AC Source," IEEE Trans. Power Electron., vol. 30, no. 3, pp. 1591-1604, March 2015.

[7] B. Yin, R. Oruganti, S. K. Panda and A. K. S. Bhat, "An Output-Power-Control Strategy for a Three-Phase PWM Rectifier Under Unbalanced Supply Conditions," IEEE Trans. Ind. Electron., vol. 55, no. 5, pp. 2140-2151, May 2008

[8] M. M. Shabestary and Y. A. I. Mohamed, "Analytical Expressions for Multiobjective Optimization of Converter-Based DG Operation Under Unbalanced Grid Conditions," IEEE Trans. Power Electron., vol. 32, no. 9, pp. 7284-7296, Sept. 2017.

[9] M. M. Shabestary and Y. A. I. Mohamed, "Advanced Voltage Support and Active Power Flow Control in Grid-Connected Converters Under Unbalanced Conditions," IEEE Trans. Power Electron., vol. 33, no. 2, pp. 1855-1864, Feb. 2018.

[10] J. Miret, A. Camacho, M. Castilla, L. G. de Vicuña and J. Matas, "Control Scheme With Voltage Support Capability for Distributed Generation Inverters Under Voltage Sags," IEEE Trans. Power Electron., vol. 28, no. 11, pp. 5252-5262, Nov. 2013.

[11] A. Camacho, M. Castilla, J. Miret, J. C. Vasquez and E. Alarcon-Gallo, "Flexible Voltage Support Control for Three-Phase Distributed Generation Inverters Under Grid Fault," IEEE Trans. Ind. Electron., vol. 60, no. 4, pp. 1429-1441, April 2013.

[12] F. Nejabatkhah, Y. W. Li and B. Wu, "Control Strategies of Three-Phase

[13] Distributed Generation Inverters for Grid Unbalanced Voltage Compensation," IEEE Trans. Power Electron., vol. 31, no. 7, pp. 5228-5241, July 2016.

[14] P. Cheng, C. Chen, T. Lee and S. Kuo, "A Cooperative Imbalance Compensation Method for Distributed-Generation Interface Converters," IEEE Trans. Ind. Appl., vol. 45, no. 2, pp. 805-815, March-april 2009.

[15] X. Zhao, J. M. Guerrero, M. Savaghebi, J. C. Vasquez, X. Wu and K. Sun, "Low-Voltage Ride-Through Operation of Power Converters in Grid-Interactive Microgrids by Using Negative-Sequence Droop Control," IEEE Trans. Power Electron., vol. 32, no. 4, pp. 3128-3142, April 2017.

[16] R. Kabiri, D. G. Holmes and B. P. McGrath, "Control of Active and Reactive Power Ripple to Mitigate Unbalanced Grid Voltages," IEEE Trans. Ind. Appl., vol. 52, no. 2, pp. 1660-1668, March-April 2016.

[17] F. Wang, J. L. Duarte and M. A. M. Hendrix, "Pliant Active and Reactive Power Control for Grid-Interactive Converters Under Unbalanced Voltage Dips," IEEE Trans. Power Electron., vol. 26, no. 5, pp. 1511-1521, May 2011

[18] X. Guo, W. Liu and Z. Lu, "Flexible Power Regulation and Current-Limited Control of the Grid-Connected Inverter Under Unbalanced Grid Voltage Faults," IEEE Trans. Ind. Electron., vol. 64, no. 9, pp. 7425-7432, Sept. 2017.

[19] A. Camacho, M. Castilla, J. Miret, A. Borrell and L. G. de Vicuña, "Active and Reactive Power Strategies With Peak Current Limitation for Distributed Generation Inverters During Unbalanced Grid Faults," IEEE Trans. Ind. Electron., vol. 62, no. 3, pp. 1515-1525, March 2015.

[20] K. Sun, X. Wang, Y. W. Li, F. Nejabatkhah, Y. Mei and X. Lu, "Parallel Operation of Bidirectional Interfacing Converters in a Hybrid AC/DC Microgrid Under Unbalanced Grid Voltage Conditions," IEEE Trans. Power Electron., vol. 32, no. 3, pp. 1872-1884, March 2017.

[21] E. Afshari et al., "Control Strategy for Three-Phase Grid-Connected PV Inverters Enabling Current Limitation Under Unbalanced Faults," IEEE Trans. Ind. Electron., vol. 64, no. 11, pp. 8908-8918, Nov. 2017.

[22] M. Nasiri and R. Mohammadi, "Peak Current Limitation for Grid Side Inverter by Limited Active Power in PMSG-Based Wind Turbines During Different Grid Faults," IEEE Trans. Sustain. Energy, vol. 8, no. 1, pp. 3-12, Jan. 2017.

[23] Y. Chang, J. Hu, W. Tang and G. Song, "Fault Current Analysis of Type-3 WTs Considering Sequential Switching of Internal Control and Protection Circuits in Multi Time Scales During LVRT," IEEE Trans. Power Syst., vol. 33, no. 6, pp. 6894-6903, Nov. 2018.
[24] I. Erlich, J. Kretschmann, J. Fortmann, S. Mueller-Engelhardt and H. Wrede, "Modeling of Wind Turbines Based on Doubly-Fed Induction Generators for Power System Stability Studies," IEEE Trans. Power Syst., vol. 22, no. 3, pp. 909-919, Aug. 2007.

[25] R. Cardenas, R. Pena, S. Alepuz and G. Asher, "Overview of Control Systems for the Operation of DFIGs in Wind Energy Applications," IEEE Trans. Ind. Electron., vol. 60, no. 7, pp. 2776-2798, July 2013.

[26] G. Pannell, D. J. Atkinson and B. Zahawi, "Minimum-Threshold Crowbar for a Fault-Ride-Through Grid-Code-Compliant DFIG Wind Turbine," IEEE Trans. Energy Convers., vol. 25, no. 3, pp. 750-759, Sept. 2010.

[27] L. G. Meegahapola, T. Littler and D. Flynn, "Decoupled-DFIG Fault Ride-Through Strategy for Enhanced Stability Performance During Grid Faults," IEEE Trans. Sustain. Energy, vol. 1, no. 3, pp. 152-162, Oct. 2010

[28] Y. Shen, D. Ke, Y. Sun, D. S. Kirschen, W. Qiao and X. Deng, "Advanced Auxiliary Control of an Energy Storage Device for Transient Voltage Support of a Doubly Fed Induction Generator," IEEE Trans. Sustain. Energy, vol. 7, no. 1, pp. 63-76, Jan. 2016.

[29] S. B. Naderi, M. Negnevitsky and K. M. Muttaqi, "A Modified DC Chopper for Limiting the Fault Current and Controlling the DC-Link Voltage to Enhance Fault Ride-Through Capability of Doubly-Fed Induction-Generator-Based Wind Turbine," IEEE Trans. Ind. Appl., vol. 55, no. 2, pp. 2021-2032, March-April 2019.

[30] A. M. A. Haidar, K. M. Muttaqi and M. T. Hagh, "A Coordinated Control Approach for DC link and Rotor Crowbars to Improve Fault Ride-Through of DFIG-Based Wind Turbine," IEEE Trans. Ind. Appl., vol. 53, no. 4, pp. 4073-4086, July-Aug. 2017.

[31] M. Castilla, J. Miret, A. Camacho, J. Matas and L. García de Vicuña, "Voltage Support Control Strategies for Static Synchronous Compensators Under Unbalanced Voltage Sags," IEEE Trans. Ind. Electron., vol. 61, no. 2, pp. 808-820, Feb. 2014.

[32] Y. Xia, W. Wei, M. Yu and P. Wang, "Stability Analysis of PV Generators With Consideration of P\&O-Based Power Control," IEEE Trans. Ind. Electron., vol. 66, no. 8, pp. 6483-6492, Aug. 2019.

[33] Y. Xia, M. Yu, X. Wang and W. Wei, "Describing Function Method Based Power Oscillation Analysis of LCL-Filtered Single-Stage PV Generators Connected to Weak Grid," IEEE Trans. Power Electron., vol. 34, no. 9, pp. 8724-8738, Sept. 2019.

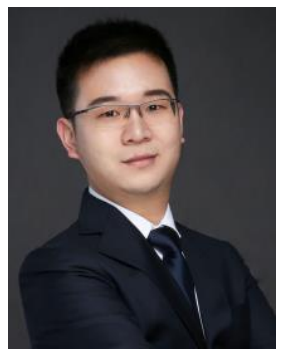

Yanghong Xia (S'16-M'19) received the B.S. degree in automation from the College of Automation, Huazhong University of Science and Technology (HUST), Wuhan, China, and Ph.D degree in control theory and control engineering from the College of Electrical Engineering, Zhejiang University (ZJU), Hangzhou, China, in 2014 and 2019, respectively. Now, he is a Post-doctoral Research Fellow in the joint postdoctoral fellowship program between ZJU and University of Cambridge, Cambridge, U.K.

His current research interests include advanced control methods, stability analysis of power system, hybrid ac/dc microgrids.

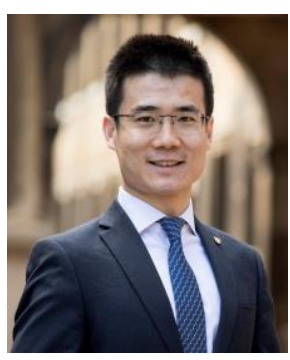

Teng Long (M'13) received the B.Eng. degree from the College of Electrical Engineering, Huazhong University of Science and Technology (HUST), Wuhan, China, the first class B.Eng. (Hons.) degree from the University of Birmingham, Birmingham, U.K., in 2009, and the Ph.D. degree from the University of Cambridge, Cambridge, U.K. in 2013. Until 2016, he was a Power Electronics Engineer with the General Electric (GE) Power Conversion business in 
Rugby, U.K. He is currently a Lecture with the University of Cambridge.

His current research interests include power electronics, electrical machines, and the machine drives. Dr. Long is a Chartered Engineer (CEng) registered with the Engineering Council in the U.K. 